\title{
CORTISONE IN HYPERTENSIVE VASCULAR DISEASE ${ }^{1}$
}

\author{
By GEORGE A. PERERA, THOMAS C. FLEMING, KERMIT L. PINES, AND \\ MARGARET CRYMBLE
}

\author{
(From the Departments of Medicine and Physiology, College of Physicians and Surgeons, \\ Columbia University, and the Presbyterian Hospital, New York)
}

(Submitted for publication February 23, 1950; accepted, February 27, 1950)

Previous observations have indicated that the administration of cortisone may be associated with a decline in blood pressure in patients with uncomplicated hypertensive vascular disease (1). As the changes in arterial tension were comparatively small in these short-term studies, and usually took place immediately after the steroid had been discontinued, it seemed desirable to record the effects of increased dosage given for a longer period of time.

\section{CASE REPORT}

M. J., a 37-year-old Negro housewife, was admitted to the metabolism ward of the Presbyterian Hospital because of occasional headaches of moderate intensity, palpitations and hypertension known for five years. There was neither past nor present evidence of cardiac pain, congestive failure, renal, cerebral or obvious endocrine disease. Physical examination was not remarkable except for a blood pressure of $210 / 128$ and slight arteriolar narrowing and arteriovenous compression on funduscopic examination.

The patient was afebrile throughout the period of observation. Complete blood count, circulation time and venous pressure were within normal limits. Popliteal arterial pressures were not reduced. X-ray of the heart disclosed no hypertrophy and the electrocardiogram showed no significant abnormalities. Repeated urinalyses were negative; the urine concentrated to a specific gravity of 1.022; the phenolsulfonphthalein excretion was 80 per cent in two hours; and an intravenous pyelogram was normal. A benzodioxane test did not suggest the presence of a pheochromocytoma (2).

\section{METHODS}

The patient was kept in bed until after blood studies and blood pressure measurements were made, and ambulatory activity was standardized at a constant level during the rest of the day. She was weighed daily before breakfast on the same scales. Distilled water was supplied for drinking. "Resting" blood pressures were measured each morning in the same arm by the same observer,

1 This investigation was supported (in part) by research grants from the National Heart Institute, U.S.P.H.S., and was aided through the generosity of the Albert and Mary Lasker Foundation and the Albert $\mathrm{H}$. and Jessie D. Wiggin Foundation. with the subject quiet and relaxed in bed, the head of which was raised to a 30-degree angle. At least seven readings were taken at half-minute intervals and the lowest systolic and lowest diastolic values recorded.

Throughout the study the patient was given a constant diet and fluid intake: identical salt-poor daily menus (2,060 calories, including $62 \mathrm{gms}$. of protein and $268 \mathrm{gms}$. of carbohydrate), dietary sodium chloride and added salt administered in constant amounts in weighed salt shakers (totalling by direct analysis 75.7 milliequivalents per 24 hours), and a daily fluid intake of $1,770 \mathrm{cc}$. Chemical and laboratory determinations were undertaken by methods previously described (1). The cardiac output was calculated from ballistocardiographic tracings, taken serially throughout the study. ${ }^{2}$

In order to secure an adequate baseline, preliminary observations were carried out for 34 days. An independent investigation of the effects of potassium thiocyanate $(0.5$ gm. daily by mouth) was undertaken from the 11th to the 17 th hospital day, but serum thiocyanate levels had returned to negligible values before the next phase of the study. The patient then received cortisone acetate (Merck), $50 \mathrm{mgs}$. intramuscularly every six hours for a period of 30 days. This was followed by a week's period of placebo injections intramuscularly $(1 \mathrm{cc}$. of 5 per cent glucose).

\section{RESULTS}

The administration of cortisone acetate (200 mgs. daily) was associated with several minor subjective changes. The patient complained of moderate insomnia and noted an increased appetite. These symptoms disappeared within two days after the steroid was discontinued. Headaches and palpitation vanished during the treatment period and returned only to a slight extent several weeks later.

The patient's appearance changed in that her face seemed slightly fuller and more rounded, and a slight acneiform eruption developed during the final week of therapy. She also was aware of

${ }^{2}$ We are indebted to Dr. H. B. Hamilton for "corticoid" determinations, to Dr. J. W. Jailer for 17-ketosteroid measurements, and to Dr. S. E. Bradley for renal clearance studies. Ballistocardiograms were obtained with a low frequency, critically-damped instrument under the supervision of Dr. J. L. Nickerson. 
a major increase in the loss of scalp hair. Again there was a slow reversal of these manifestations when the cortisone was stopped. Three days before the cessation of treatment, the patient developed a furuncle on the medial left breast from which a hemolytic staphylococcus aureus was cultured. There was no systemic reaction to this infection. This lesion rapidly extended, became covered by a black crust $1 \mathrm{~cm}$. in diameter, then showed rapid sloughing and failure of healing with abundant, thick, purulent material in a crater 2 cms. wide and $1.5 \mathrm{cms}$. deep. Despite local penicillin and bacitracin ointment, which cleared the surface infection, no epithelial and granulation tissue was evident on inspection until six days after steroid administration had been discontinued. Healing then took place at a normal rate.

While receiving cortisone, there was no alteration in the time or duration of the menstrual cycle or in the menstrual flow, except for the appearance

TABLE I

Laboratory data of a hypertensive patient treated with cortisone

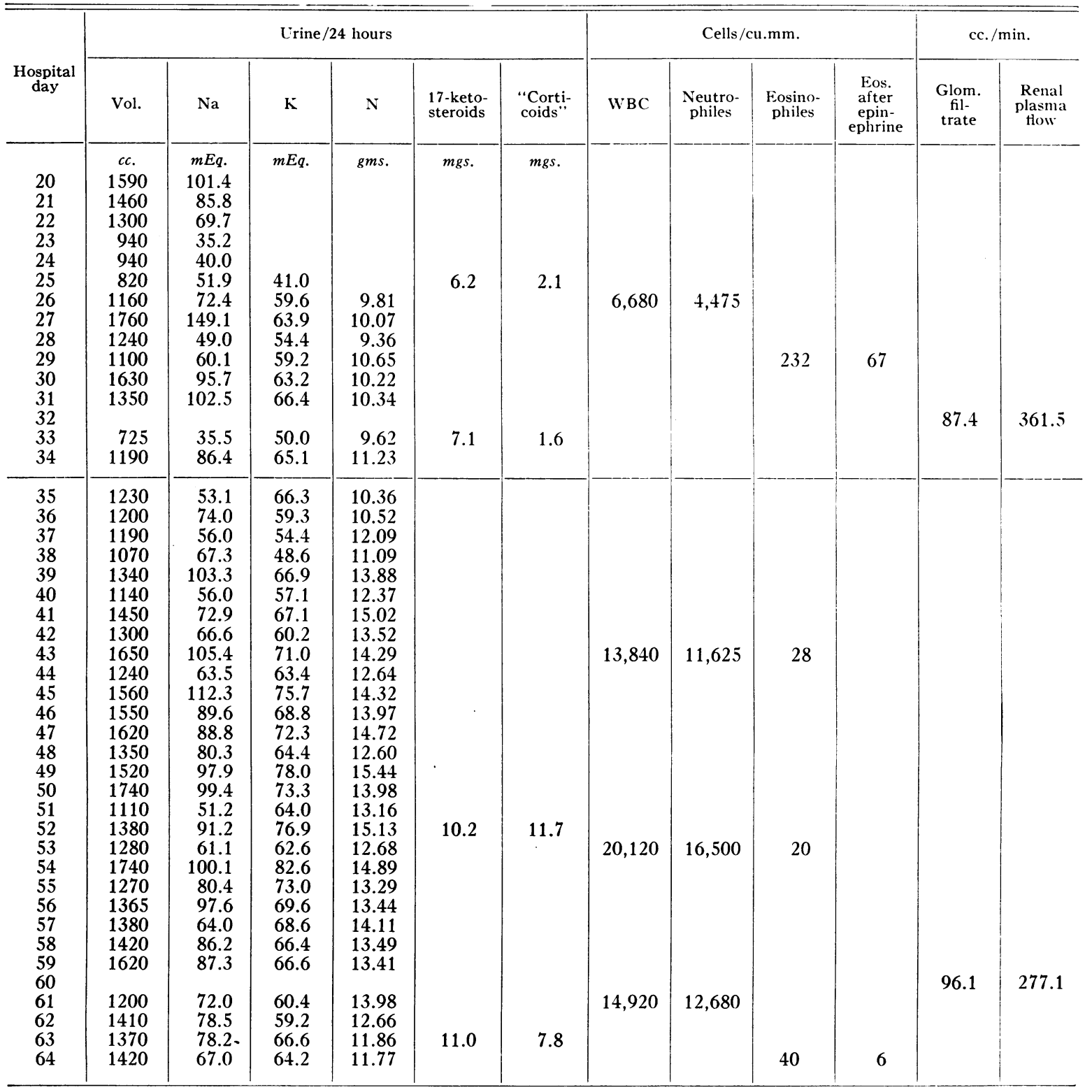


TABLE I-Continued

\begin{tabular}{|c|c|c|c|c|c|c|c|c|c|c|c|c|}
\hline \multirow[b]{2}{*}{$\begin{array}{c}\text { Hospital } \\
\text { day }\end{array}$} & \multicolumn{6}{|c|}{ Urine $/ 24$ hours } & \multicolumn{4}{|c|}{ Cells/cu.mm. } & \multicolumn{2}{|c|}{ cc. $/ \mathrm{min}$} \\
\hline & Vol. & $\mathrm{Na}$ & $\mathbf{K}$ & $\mathbf{N}$ & $\begin{array}{l}\text { 17-keto- } \\
\text { steroids }\end{array}$ & $\begin{array}{l}\text { "Corti- } \\
\text { coids" }\end{array}$ & WBC & $\begin{array}{l}\text { Neutro- } \\
\text { philes }\end{array}$ & $\begin{array}{l}\text { Eosino- } \\
\text { philes }\end{array}$ & $\begin{array}{l}\text { Eos. } \\
\text { after } \\
\text { epin- } \\
\text { ephrine }\end{array}$ & $\begin{array}{c}\text { Glom. } \\
\text { fil- } \\
\text { trate }\end{array}$ & $\begin{array}{c}\text { Renal } \\
\text { plasma } \\
\text { flow }\end{array}$ \\
\hline $\begin{array}{l}65 \\
66 \\
67 \\
68 \\
69 \\
70 \\
71 \\
72 \\
73 \\
74 \\
75 \\
76 \\
77 \\
78 \\
79 \\
80 \\
81 \\
82 \\
83 \\
84 \\
85 \\
86 \\
87 \\
88 \\
89\end{array}$ & $\begin{array}{r}c c . \\
1340 \\
1940 \\
1870 \\
1440 \\
1450 \\
1200 \\
1440 \\
1140 \\
1030 \\
1200 \\
1280 \\
1350 \\
960 \\
840 \\
1220 \\
1260 \\
980 \\
1070 \\
1090 \\
570 \\
1000 \\
1400 \\
1220 \\
1330 \\
980\end{array}$ & $\begin{array}{r}m E q . \\
71.0 \\
142.8 \\
150.9 \\
119.7 \\
109.9 \\
71.1 \\
76.3 \\
58.5 \\
54.0 \\
48.1 \\
83.0 \\
77.2 \\
62.4 \\
37.1 \\
78.6 \\
92.0 \\
72.4 \\
57.2 \\
83.6 \\
27.7 \\
58.6 \\
91.4 \\
76.4 \\
84.4 \\
60.0\end{array}$ & $\begin{array}{l}m E q . \\
55.9 \\
55.3 \\
41.9 \\
36.3 \\
38.1 \\
43.0 \\
48.2 \\
48.9 \\
48.6 \\
50.8 \\
63.4 \\
60.3 \\
57.4 \\
41.8 \\
59.5 \\
58.2 \\
55.9 \\
57.6 \\
51.0 \\
35.9 \\
53.1 \\
59.6 \\
49.3 \\
53.2 \\
51.4\end{array}$ & $\begin{array}{c}g m s . \\
10.68 \\
12.51 \\
10.56 \\
9.58 \\
9.39 \\
8.91 \\
8.54 \\
7.07 \\
6.29 \\
5.78 \\
6.92 \\
6.22 \\
5.42 \\
4.60 \\
5.50 \\
5.18 \\
5.86 \\
5.86 \\
5.29 \\
3.99 \\
5.41 \\
5.87 \\
5.03 \\
5.26 \\
5.40\end{array}$ & mgs. & mgs. & $\begin{array}{r}11,400 \\
8,800\end{array}$ & $\begin{array}{l}9,348 \\
6,424\end{array}$ & $\begin{array}{l}140 \\
118 \\
112 \\
\\
160\end{array}$ & $\begin{array}{c}140 \\
107^{*} \\
115 \\
45\end{array}$ & & \\
\hline
\end{tabular}

* After adrenocorticotropic hormone (25 mgs.).

of blood clots which the patient had never noticed before. A sanguineous nasal discharge and ecchymoses adjacent to venepunctures were also apparent near the close of the treatment period. However, catamenia was delayed in the postcontrol period and had not been resumed by the time the patient left the hospital. No other manifestations of Cushing's syndrome were noted, and no mental or emotional changes were observed. Repeated electroencephalograms showed identical normal patterns.

Further results are shown in Figure 1 and Table I. Although no definite initial retention could be determined, a diuresis of salt and water followed the discontinuation of cortisone, with reciprocal changes in urinary potassium excretion. The plasma volume was not modified significantly. Nevertheless, the patient's weight decreased in association with a conspicuous increase in the excretion of nitrogen in the urine, and a fall in urea nitrogen and total protein values in the serum (shared equally by both albumin and globulin components). After the cessation of steroid therapy, weight gain and a positive nitrogen bal- ance appeared; equilibrium had not yet been restored by the time of hospital discharge.

While cortisone was being administered, serum sodium and chloride values were not affected materially, but there was a definite fall in serum potassium concentrations and a rise in the carbon dioxide content. The failure to observe a compensatory drop in serum chloride could not be explained. Fasting blood sugar determinations showed little fluctuation and no glycosuria appeared. However, several days after the steroid was withdrawn, the patient complained of episodes of slight weakness before meals, culminating in a brief period of intense sweating and faintness before lunch on the sixth day. Food immediately relieved this pattern and there was no subsequent recurrence of symptoms. Occasional fasting blood sugar values were well below the previous range during this post-control period. In support of the probability that this represented hypoglycemia due at least in part to temporary depression of the adrenal cortex, were the salt and water diuresis, the transitory decline in serum sodium to 133.3 milliequivalents per liter, and the failure of the 


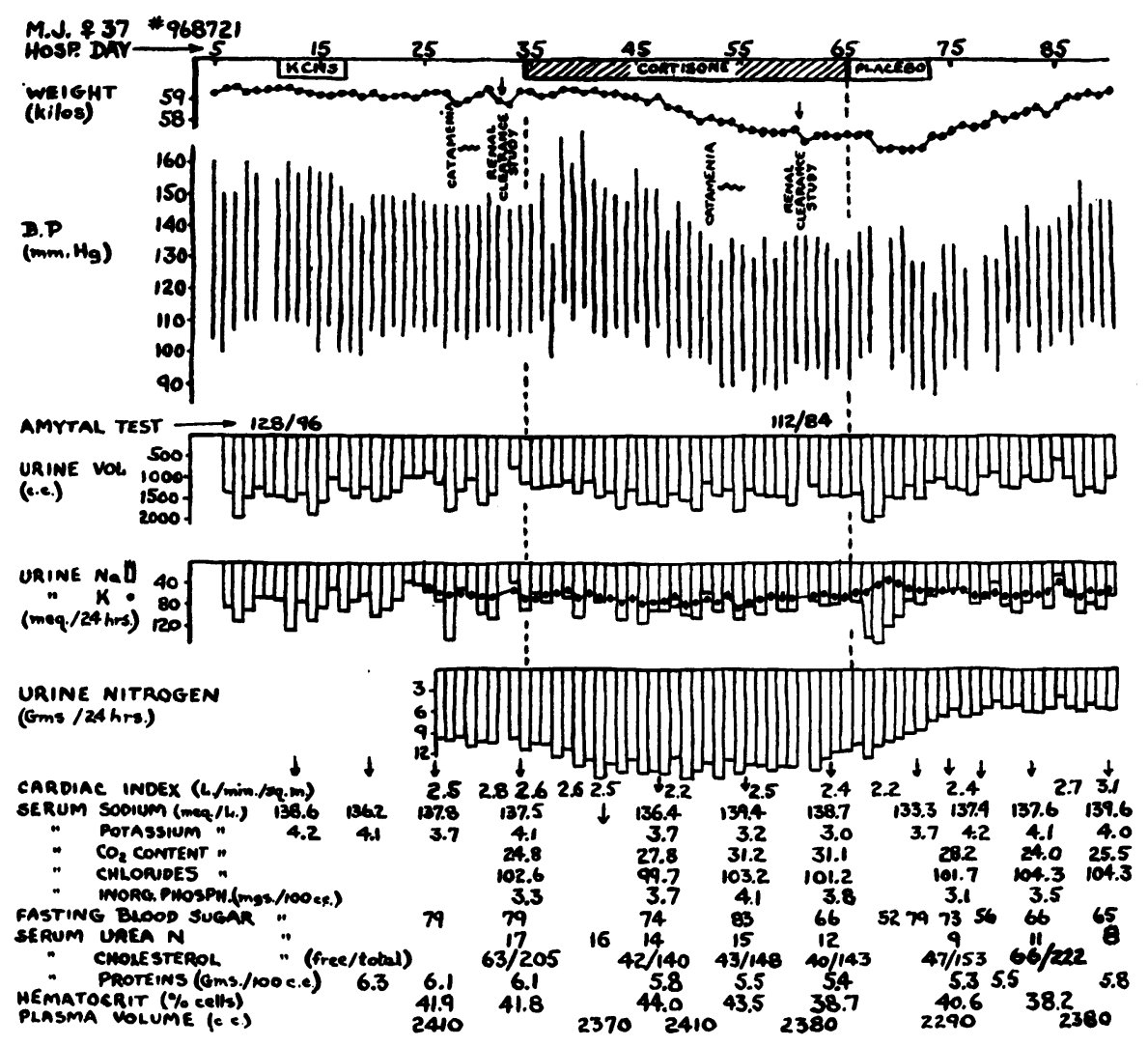

Fig. 1. Clinical and Metabolic Data of a Hypertensive Patient Treated WITH CORTISONE

eosinophile count to be modified by either epinephrine or $25 \mathrm{mgs}$. of adrenocorticotropic hormone (3). ${ }^{3}$ The administration of cortisone was associated with a definite increase in the excretion of 17-ketosteroids and "corticoids." Whereas the latter returned toward normal but did not reach control values, the 17 -ketosteroid output declined to abnormally low levels considerably later than the period of clinical hypoadrenalism and failed to increase prior to the date of hospital discharge.

Other changes observed in the course of the study included the expected leucocytosis and eosinopenia. There was a rise in serum inorganic phosphorus and a fall in both free and total cholesterol values while on cortisone. Urine specimens frequently contained large quantities of calcium phosphate crystals. Tyrosinuria developed intermittently during the first two weeks of treatment,

3 The adrenocorticotropic hormone was supplied through the generosity of Dr. John R. Mote of Armour and Company. supported by the fact that the crystals appeared identical in form to those of tyrosine and after washing gave a positive reaction by the ninhydrin method. Renal clearance studies, conducted before and near the close of the therapeutic period, disclosed the values consistent with hypertensive disease; in association with the use of cortisone there was little change in filtration rate but some further reduction in renal plasma flow. Serial electrocardiograms and teleroentgenograms showed no alterations.

The "resting" blood pressure, after an initial irregular rise, fell below control values and continued at reduced levels throughout the period of cortisone administration and for two subsequent weeks. It then returned to pretreatment levels. The average reading for the week before cortisone was $146 / 106 \mathrm{~mm}$. of mercury, with a reduction to an average of 134/93 in the final week of therapy. During this period there was a minor reduction in pulse rate and a slight trend toward lower cardiac 
output values. However, the blood pressure readings during ballistocardiographic studies were generally above the "resting" values.

\section{DISCUSSION}

In the present study, cortisone was administered for a prolonged period using doses in excess of those generally employed in other clinical trials. Although it is unwise to draw conclusions from a single case report, certain features of this study deserve comment.

The minor subjective effects noted in this patient and the absence of significant mental or electroencephalographic changes suggest at least quantitative differences from the response that has been produced by the adrenocorticotropic hormone (4, 5). Insomnia has been observed before (1). The behavior of the furuncle in this patient recalls the profound disturbance in the formation of granulation tissue reported by Ragan and his associates $(5,6)$, and raises serious questions concerning the safety of cortisone when administered to surgical patients or to those with infectious disease.

Considering the dosage employed, the fluid and electrolyte changes were surprisingly small. On the other hand, there were profound alterations in nitrogen balance, reflected also in body weight, urea nitrogen and serum protein values, without concomitant evidence of gluconeogenesis. An increased catabolism or failure of anabolism of body proteins affords the probable explanation, but further study is indicated including information pertaining to renal thresholds and clearances of amino acids.

There is little doubt that the withdrawal of cortisone in this patient was associated with a temporary period of hypoadrenalism. Both carbohydrate and salt and water metabolism were affected for a short period, and there was a delayed but more sustained depression of 17-ketosteroid excretion. The transitory failure of the eosinophile count to be modified by either epinephrine or the adrenocorticotropic hormone provided further indication of adrenal cortical hypofunction. Whether prolonged overdosage with cortisone carries with it the danger of permanent adrenal cortical insufficiency cannot be determined by this study, but it does call attention to possible serious reactions which may follow discontinuance of the steroid under these conditions.

The reduction in "resting" blood pressure was small but directionally similar to that reported previously in other hypertensive patients (1). From the hemodynamic standpoint, it is clear that alterations in plasma volume were not responsible. Although open to question, the simultaneous slight fall in cardiac output affords a possible contributory mechanism.

The method by which cortisone induces a circulatory effect remains to be explained. Whereas the arterial pressure appeared to fall after therapy in the shorter-term studies, the drop observed in this patient appeared after a preliminary rise but during the period of cortisone treatment. It cannot, therefore, be attributed alone to changes following the cessation of steroid administration. Alterations in renal hemodynamics cannot be excluded as an etiological factor. One might attempt to relate the decrease in arterial tension to the weight and nitrogen loss; it should be pointed out, however, that in the previous study of hypertensive patients on cortisone (1) an effect was apparent in the absence of significant weight change and with minimal alterations in nitrogen balance. The difference in response of the adrenalectomized animal or the patient with Addison's disease, as well as the delay in response, have been used as arguments that the depressor effect is not a direct humoral action of cortisone (7). Nevertheless, the possibility remains that the primary influence of cortisone on blood pressure is exerted through modification of other hormones of the adrenal cortex. This hypothesis can only be established after further metabolic and hemodynamic study.

\section{CONCLUSIONS}

1. Clinical and metabolic studies were undertaken in a patient with uncomplicated hypertensive vascular disease to determine the effects of cortisone acetate administration in doses of $200 \mathrm{mgs}$. daily for one month.

2. Insomnia, increased appetite, increased loss of scalp hair, menstrual changes and delayed healing of a superficial pyogenic abscess were among the manifestations observed during steroid therapy.

3. In the dosage employed, cortisone adminis- 
tration induced negligible fluid, electrolyte or carbohydrate changes, a marked negative nitrogen balance, $a$ fall in serum potassium and cholesterol concentrations, an increase in serum inorganic phosphorus, transitory tyrosinuria, some increase in 17-ketosteroid and "corticoid" excretion, a decrease in renal plasma flow and an apparent small decline in cardiac output.

4. Cessation of therapy was associated with the temporary appearance of the signs and symptoms of hypoadrenalism.

5. Following a preliminary rise, there was a small but definite decline in "resting" blood pressure which appeared while the patient was receiving the steroid and which persisted for several weeks after it had been discontinued.

\section{BIBLIOGRAPHY}

1. Perera, G. A., Pines, K. L., Hamilton, H. B., and Vislocky, K., Clinical and metabolic study of 11dehydro-17-hydroxy-corticosterone acetate (Kendall compound E) in hypertension, Addison's disease and diabetes mellitus. Am. J. Med., 1949, 7, 56.

2. Goldenberg, M., Snyder, C. H., and Aranow, H., Jr., New test for hypertension due to circulating epinephrine. J.A.M.A., 1947, 135, 971.

3. Thorn, G. W., Forsham, P. H., Prunty, F. T. G., and Hills, A. G., A test for adrenal cortical insufficiency; the response to pituitary adrenocorticotropic hormone. J.A.M.A., 1948, 137, 1005.

4. Hench, P. S., Kendall, E. C., Slocumb, C. H., and Polley, H. F., The effect of a hormone of the adrenal cortex (17-hydroxy-11-dehydrocorticosterone: compound $\mathrm{E}$ ) and of pituitary adrenocorticotropic hormone on rheumatoid arthritis; preliminary report. Proc. Staff Meet. Mayo Clinic, 1949, 24, 181.

5. Ragan, C., Grokoest, A. W., and Boots, R. H., Effect of adrenocorticotrophic hormone (ACTH) on rheumatoid arthritis. Am. J. Med., 1949, 7, 741.

6. Ragan, C., Howes, E. L., Plotz, C. M., Meyer, K., and Blunt, J. W., Effect of cortisone on production of granulation tissue in the rabbit. Proc. Soc. Exper. Biol. \& Med., 1949, 72, 718.

7. Perera, G. A., The adrenal cortex and hypertension. Bull. N. Y. Acad. Med., 1949, 26, 75. 